\title{
Patologias do Vazio: um Desafio à Prática Clínica Contemporânea
}

\author{
Void pathologies: a challenge for contemporary clinic practice
}

Resumo: Este trabalho procura apresentar as patologias do vazio, que incluem diagnósticos como os transtornos borderline e narcisista de personalidade, o conceito de falso self e o autismo. O presente texto baseou-se em pesquisa bibliográfica sobre a teoria da técnica psicanalítica. A teoria do desenvolvimento, principalmente a obra de Donald Winnicott foi usada para compreender essas patologias regressivas. Uma análise de fragmento literário e um caso clínico estabelecem a ligação entre teoria e prática.

Palavras-Chave: Psicoterapia, prática clínica, patologias do vazio, teoria winnicottiana.

Abstract: This work aims to present the void pathologies, which include diagnoses as borderline and narcissist disorders of personality, the concept of false self and autism. The present paper is based on bibliographical research on the theory of psychoanalytical technique. The development theory (mainly Donald Winnicott's work) was used to understand these regressive pathologies. An analysis of a literary fragment and of a clinical case establish the link between theory and practice.

Key Words: Psychotherapy, clinic practice, void pathologies, Winnicott's theory.

\section{Evanisa Helena Maio de Brum}

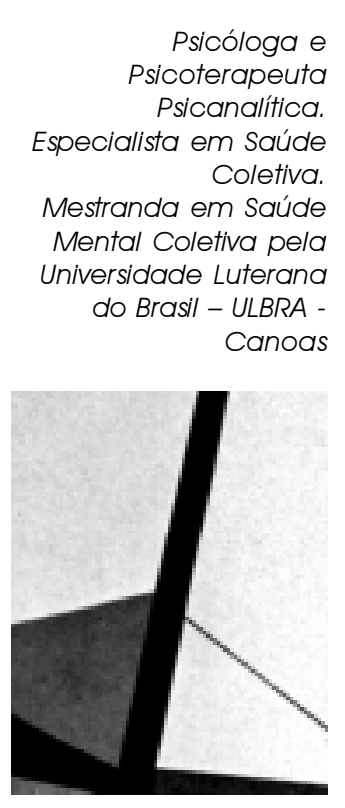

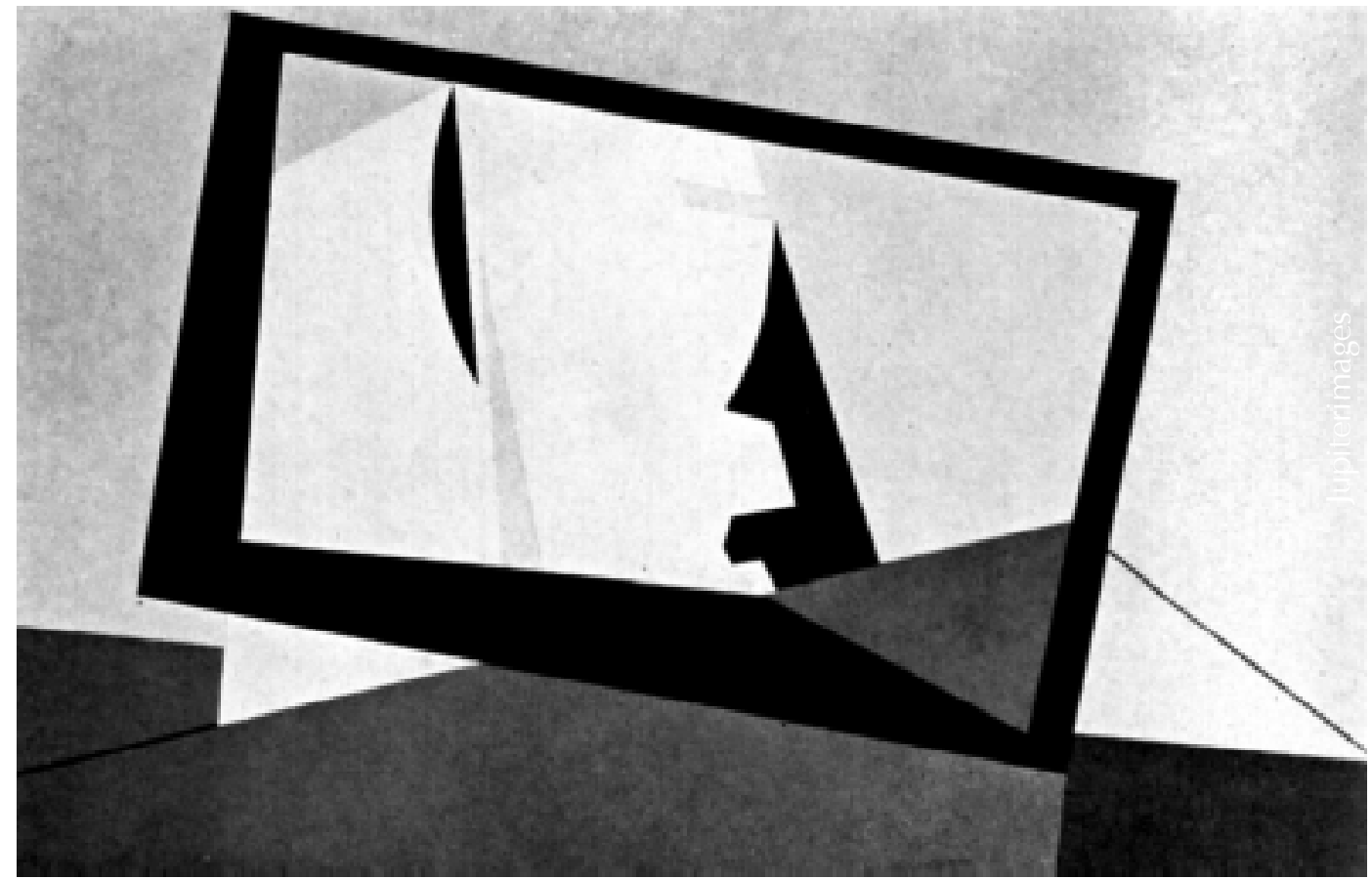

Através dos textos literários, podemos conhecer de perto as inquietudes da alma humana; dessa forma, a literatura transforma-se em um instrumento capaz de auxiliar-nos na compreensão do funcionamento psíquico. $\mathrm{O}$ aprendizado sobre a utilização da literatura na Psicanálise, obtivemos de Freud, pois encontramos essa influência na construção de sua teoria, seja de forma direta, seja indireta. Freud utilizou, em sua vasta produção, autores como Sófocles, Goethe, Schakespeare, Dostoievsky, Hoffmann, entre outros (SBP DE PA, 2003). Sabiamente, intuiu que a verdade humana se encontra nos textos literários quando acolhem e dão forma aos desejos e às pulsões do homem (Masina, 2003). Assim como Freud, muitos de seus seguidores utilizaram a literatura na formulação de seus trabalhos em Psicanálise. Dessa forma, no presente artigo, também fazemos uso de um fragmento literário na tentativa de compreender o mundo interno humano, mais especificamente, as patologias do vazio. Tais patologias surgem, na contemporaneidade, como um desafio para a Psicanálise; é necessário que possamos voltar a nossa atenção para os estudos desses diagnósticos, buscando a melhor forma de compreendê-los e tratá-los. Para abordar tal questão, começamos 
contando parte da história de autoria da escritora gaúcha Letícia Wierzchowski (1999).

"Meu filho Theodoro cresceu e percebi que era mesmo um caçador de verdades, das mais simples às mais complexas, desvendando o mundo com um olhar do qual nada escapava; tinha a facilidade de antever as coisas.

Amparo nos chegou em uma dessas tantas excursões que Theodoro fazia pelas ruas da cidade. Empoleirado na carroça, o menino ia e vinha e trazia qualquer coisa que pudesse. $\mathrm{Na}$ primeira tarde em que a vi, pareceu-me com qualquer desses cãezinhos que Théo recolhia das estradas, e assim recordei-me dela por todos os anos. Era uma coisinha pequena e recoberta de imundícies, enrolada em uns trapos velhos e duros de pó. Escondida num canto da carroça, agarrada às próprias pernas, os cabelos sujos e emaranhados. Théo disse-me que era muda, mas que ouvia tudo perfeitamente.

Amparo, a muda, era tão quieta que eu chegava a esquecer-me de sua existência. Assim, Amparo cresceu, sem voz e sem sobrenome, confundindose com a sombra de meu filho, silenciosa. Mais tarde, Theodoro já lhe contava os futuros que antevia; ensinou-Ihe a ver a alma dos viventes. Ela bebia-Ihe cada palavra, mergulhada em seu mundo de silêncio, e entregava-se ao prazer de imitar aquele menino dourado.

Depois de Théo, vinha sempre Amparo, porque não sabiam ser um sem o outro. Quando a noite caía e todos recolhiam-se aos quartos, lá se ia Amparo, enredada em seus panos, colar seu corpo à porta de meu filho, na ânsia de captar seus sonhos pelas frestas de madeira. Ela bebia-lhe os risos cálidos e os poemas sussurrados, e, assim, lentamente, em seu mundo de silêncios, começava a brotar um novo universo, porque o sentimento que the nascia fazia crescer sua alma.

Com o tempo, Theodoro ensinou-a a ler, decifrando os doces volteios da escrita com a calma e a paciência de um apóstolo. Nunca mais, para ela, haveria a solidão, e a mudez de estátua era coisa que esquecia quando mergulhava nas páginas dos livros.

Desde que meu filho pressentira sua morte, uma tristeza silente impregnara-se no fundo de seus olhos. Naquele dia, pensou: "hoje irei à praia e levarei Amparo comigo; fechou os olhos para se sentir, e foi então que, no escuro de si mesmo, percebeu que faltava algo. Faltava Amparo. Theodoro sentiu que seu coração se descompassou... Ela havia aprendido com ele a ler as almas...
Após algumas tardes da morte de meu filho, percebi que havia-me esquecido que existira, entre nós, Amparo. Esquecera-me porque, com o fim dos risos cálidos de Théo, parecera-me normal que Amparo também nos sumisse. Procuramos Amparo por todos os cantos e não a encontramos. Depois disso, matutei muitos dias sobre a muda Amparo, a quem limpei as imundícies e que, por tantos anos, seguira meu filho feito uma sombra ou um prolongamento de seu corpo. Tanto pensei e repensei que, confusa, decidi que não havia existido. Por fim, vencida por outras certezas e lembranças, acabei aceitando a existência e o desaparecimento de Amparo, a muda e, mais tarde, atribuí-Ihe o doce episódio das rosas brancas deixadas diariamente sobre o túmulo de meu filho. Amparo agora vivia em algum lugar longe de nossa casa." FIM.

Partimos dessa história para refletir sobre as patologias do vazio como um desafio à prática clínica contemporânea, e indagamos : qual seria a abordagem terapêutica com esses pacientes?

Muitos dos pacientes contemporâneos são um pouco Amparo, chegam buscando muito mais do que serem compreendidos; buscam existir, serem olhados, encontrados, como Amparo o foi por Theodoro.

Na época em que Freud formulou sua teoria, os conflitos de seus pacientes eram vistos com base na teoria da sexualidade (Freud, 1905a/1999), que ele postulou no início do século, e a partir da qual propôs uma técnica de abordagem - a técnica psicanalítica. Seus pacientes, nesse contexto, eram mais Theodoros ${ }^{1}$ do que Amparos. Para atender Theodoro, usaríamos os legados deixados por Freud, interpretando as associações livres através do uso da palavra, muitas vezes entendendo o não-falado como resistência ao tratamento e à cura (Freud, 1937/1999).

Se hoje recebermos Amparo e qualificarmos sua mudez como resistência, criaremos um abismo ainda maior do que o já existente, e seu mundo interno seguirá sem a oportunidade de ser decifrado. O funcionamento psíquico de Amparo enquadra-se no que tem sido intitulado patologias do vazio, referindo-se aos pacientes com transtornos de personalidade borderline, narcisista (American Psychiatric Association, 1995), pacientes com falso self (Winnicott,1960/1982) ou, ainda, ao que Zimerman (2001) se refere ao citar a obra de Tustin e sua denominação pacientes autistas, os quais se encontram em um estado mental de desistência, em cujo caso o único desejo é o de não desejar. Denominações diferentes para se dizer que são pacientes que sofrem de vazios, vazios esses oriundos de falhas precoces no primitivo vínculo
Meu agradecimento à psicanalista Ivanosca Martini pelas importantes sugestões, as quais muito contribuíram para a produção deste artigo.

1 Compreende-se o funcionamento de Theodoro como neurótico. 
mãe-bebê, e os bebês crescem e transformam-se em adultos que ainda portam esses vazios.

Nos estudos vinculares, encontramos uma forma de compreender essas patologias mais regressivas a partir das teorias do desenvolvimento. Winnicott (1963a/1982), um dos autores dessa teoria, descreveu o desenvolvimento emocional primitivo em termos da jornada da dependência à independência, propondo três categorias: dependência absoluta, dependência relativa e autonomia relativa. Para ele, é na fase de dependência absoluta que a mãe desenvolve o que chamou de preocupação materna primária (Winnicott, 1956/2000). Esse estado especial da mãe, de regressão temporária, faz com que ela seja capaz de desenvolver uma sintonia fina com seu bebê, compreendendo-o por meio de uma surpreendente capacidade de identificação e constituindo-se, com ele, em uma unidade. A mãe, então, empresta ao bebê seus braços, suas pernas, seu ego e, assim, vai auxiliando-o a se integrar. Se, nessa fase, a mãe não é capaz de conectar-se com seu bebê, este fica num estado de não-integração, tornando-se apenas um corpo com partes soltas. De acordo com as idéias acerca do desenvolvimento propostas por Winnicott, é nesse momento que ocorre a falha nos pacientes aos quais me refiro, e que me parece ficarem muito bem representados pela personagem Amparo. São pacientes, assim como ela, perdidos num mundo de não- existência, sem passado, sem voz, pacientes que ainda não nasceram psicologicamente (Malher, 1975).

o uso da relaçáo transferencial segue as idéias de Winnicott. sendo, portanto, diferente do que Freud postulou. Freud (1905b/1999) conceituou transferência como novas ediçóes revistas de impulsos desejos efantasias e, em 1923, incluiu em seu conceito a participação de figuras egóicas e dos mecanismos de defesa do ego. Já para Winnicott (19556/2000), concepção que aqui adoto, a transferência é muito mais do que repetição de impulsos e defesas, especialmente com os pacientes regressivos, pois não há desejos e, sim, necessidades para serem repetidas, que devem ser intuidas pelo analista através da contratransferência, $e$ satisfeitas.

3 Vista a capacidade dos pacientes neuróticos viverem a conflitiva edípica $e$, conseqüentemente, de triangular:
Para esses pacientes, é necessário e imprescindível que ocorra uma regressão dentro do setting. A abordagem é criar um setting estável, onde uma relação de confiança e segurança possa ser construída, para que o paciente possa regredir e recriar, com o terapeuta, antigas situações de fracasso vividas com a mãe, relacionadas à época de dependência absoluta, só que, agora, com a oportunidade de serem usadas terapeuticamente através da relação transferencial ${ }^{2}$.

É ao trabalho de Balint (1968/1989) e ao de Winnicott (1954/2000) que devemos muito de nossa compreensão sobre a regressão. Foram eles que descobriram uma necessidade especial, em determinados pacientes, de usar o contexto e o processo analítico para se desfazerem do fardo do falso self e sucumbirem ao self verdadeiro. Mais tarde, Little (1981), Khan (1974), Green (1986) e Bollas (1987), entre outros, desenvolveram mais ainda nossa compreensão sobre regressão terapêutica, que pode dar-se em qualquer grau, ser limitada e momentânea, ou total e envolvendo toda a vida do paciente por um certo tempo.
No momento de regressão à dependência absoluta, o ambiente sustenta o indivíduo e este, ao mesmo tempo, nada sabe sobre o ambiente - é uno com ele. Então, haverá somente uma pessoa no setting, o próprio paciente, o que traz para o tratamento um aspecto diferente do proposto por Freud com os pacientes histéricos, ou seja, para Freud, existem três pessoas, uma delas fora do consultório ${ }^{3}$; quando existem apenas duas pessoas, terá ocorrido uma regressão do paciente no contexto, o analista representando a mãe com sua técnica, sendo o paciente, o bebê. Refiro-me, aqui, a um estado seguinte de regressão, no qual há apenas o paciente, como me ensinou uma paciente, em um momento regressivo, ao chamar-me pelo seu próprio nome.

Frente a essa situação de regressão, o contexto torna-se mais importante que a interpretação. A ênfase é transferida de um aspecto para o outro (Winnicott, 1954/2000). Em 1960, Winnicott acrescenta que devemos falar do que acontece na sessão, o que é diferente de interpretar. Um aspecto importante é que o paciente pode, nesse período de regressão, usar a falha do analista, o que o levará a uma falha antiga, que o paciente pode agora perceber e zangar-se com isso. Se o terapeuta se defende, o paciente perde a chance de zangarse com uma falha passada justamente no momento em que a raiva se tornou possível. Outra questão pontuada nesse contexto é que os intensos sofrimentos possam ser suportados, principalmente pelo terapeuta (Winnicott, 1955-6/2000).

No atendimento com esses pacientes, é necessária uma conexão empática, a fim de sermos capazes de usar expressivamente nossa contratransferência, pois quando Amparos nos procuram, elas são realmente mudas, psiquicamente mudas, não se expressam pela palavra, são pré-verbais. Em outras vezes, como ressalta Zimerman (1999), usam as palavras para não comunicar. Falam pelo corpo, demonstram seu desconforto remexendo-se na cadeira, sentem dores, falam pelos silêncios que, quando percebidos empaticamente pelo terapeuta capaz de decodificá-los e nomeá-los ao paciente no momento oportuno, passam aos poucos a adquirir significados. Nossa abordagem, frente a esses pacientes, seria a de tentar encontrar uma via de comunicação, como fez Theodoro com Amparo, que, lentamente, aproximou-se dela, fez com que se sentisse segura, amparada (seria, para nós, um setting estruturado e seguro).

É importante, também, que o paciente possa reconhecer seu vazio, sua não- existência. Winnicott, em seu texto Medo do Colapso (1963b/ 1994), menciona que, se o vazio não é experienciado como tal, desde o começo, ele aparece, então, como um estado de nãointegração, que é compulsivamente buscado. É 
somente a partir do reconhecimento da nãoexistência que a existência pode começar. Esse reconhecimento, pelo paciente, de sua inexistência poderá ser tolerado devido à dependência do ego do analista, como mostrou-me Camila, uma paciente, ao dizer: "Chego neste vazio, me dou conta, fico desesperada e saio correndo, faço festa, fico com vários homens, só que o problema é que estou amarrada num elástico, corro, corro, mas chega uma hora que o elástico não estica mais e a pressão me faz voltar para este vazio. Sei que não posso voltar a correr, que preciso desamarrar este nó do elástico. Só que para desamarrá-lo tenho que ficar aqui neste nada, neste limbo e isso me dói muito".

Winnicott (1963b/1994) relata também que, nesse estado, o paciente pode perceber o Medo do Colapso, do Vazio, como o medo do que já aconteceu, mas não foi experimentado, porque não havia um ego capaz de absorver a experiência, e o ego auxiliar da mãe estava imperfeito. Em alguns pacientes, existe a necessidade de experienciá-los, o que equivale a lembrar, nos termos da análise, de pacientes neuróticos.

Uma "Amparo" que acompanho não conseguia colocar em palavras seu desamparo, mas fazia-o constantemente através de seu corpo, pelo qual experimentava a sensação de que iria cair ao caminhar (vale ressaltar que, frente a exames médicos, nada foi encontrado que justificasse sua sensação), sensação que certamente nos fala do quanto lhe faltou holding. Esse termo foi ampliado por Winnicott (1971/1990) em sua obra, e significa segurar, impedir que caia, sossegar, tranqüilizar, amparar, fazendo com que a mãe humanize o bebê e o transforme num ser integrado. Se isso não ocorre, o corpo fica falando por si só, perdido num mundo de sensações.

Essa mesma paciente, frente a indicação de sua necessidade de aumentar o número de sessões, disse-me: "Que estranho, passei a não te ouvir, o som da rua ficou mais forte e tua imagem foi se desmanchando. O que tu estavas me falando mesmo?" Contar mais comigo bateu em seu registro do quanto não pôde se aproximar e contar com alguém que the desse amparo; sensações corporais que falam de seu desamparo.

Retomamos as citações do texto de Wierzchowski (1999), interligando-as com a teoria psicanalítica: "Depois de Théo, vinha sempre Amparo, porque não sabiam ser um sem o outro... Amparo confundia-se com a sombra de meu filho, era um prolongamento silencioso dele" (o que seria permitir que o paciente crie/recrie a unidade mãebebê, onde há uma adaptação perfeita do indivíduo ao seu ambiente e, assim, possa corrigir as falhas de uma maternagem deficiente original). "Amparo entregava-se ao prazer de imitar aquele menino dourado" (aqui, parece haver uma primeira forma de identificação na relação, a imitação). "Mais tarde, Theodoro ensinou-lhe a ler, decifrando os doces volteios da escrita, com a calma e a paciência de um apóstolo... ContavaIhe, também, os futuros que antevia; ensinou-lhe a ver a alma dos viventes. Ela bebia-Ihe cada palavra, mergulhada em seu mundo de silêncio" (podemos, assim, compreender estes trechos: a necessidade de o terapeuta funcionar como ego auxiliar, uma função holding -apoio/sustentaçãopara esses pacientes, auxiliando-os a passar de uma linguagem pré-verbal para uma linguagem verbal).

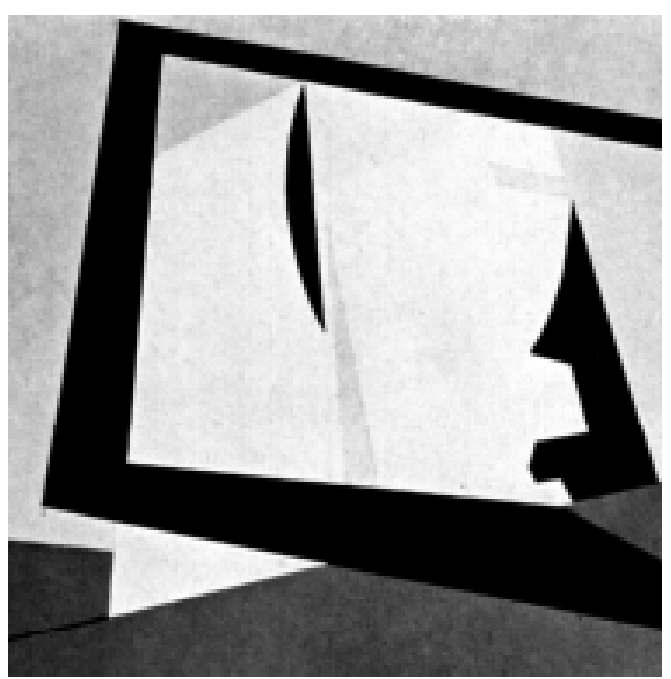

"Theodoro pensou: hoje irei à praia e levarei Amparo comigo"; fechou os olhos para se sentir, e foi então que, no escuro de si mesmo, percebeu que faltava algo. Faltava Amparo" (penso ser essa uma importante capacidade do terapeuta, ser alguém que possa usar expressivamente seus sentimentos contratransferenciais). Bollas (1987) afirma que, para trabalhar com a contratransferência com pacientes regressivos, devemos procurar o paciente dentro de nós, fazendo uma regressão contratransferencial produtiva ${ }^{4}$, sendo, segundo ele, a mesma forma usada pela mãe para se comunicar com seu bebê - "Amparo chegou e pareceu-me com qualquer desses cãezinhos que Théo recolhia das estradas" (e foi através da companhia de Théo que Amparo pôde encontrar voz em seu mundo interno mudo, ser humanizada, e, assim, lentamente, de um bichinho sobrevivente, poder construir-se como alguém no mundo).

Nós, terapeutas, temos a árdua e instigante tarefa de aprender a nos comunicar com Amparos sem
"Depois de Théo, vinha sempre Amparo, porque não sabiam ser um semo outro... Amparo confundia-se com a sombra de meu filho, era um

prolongamento silencioso dele" (o que seria permitir que o paciente crie/recrie a unidade mãe-bebê, onde há uma adaptação perfeita do indivíduo ao seu ambiente e, assim, possa corrigir as falhas de uma maternagem deficiente original)."

4 Para realizar esse tipo de regressão (Bollas, 1987), o analista necessita ser bem analisado, trabalhando a favor. da contratransferência, ou seja, permitindo-se ser ocupado pelo paciente. $O$ analista pode realizar uma clivagem produtiva do ego analitico, onde a parte ocupada pelo paciente fica doente e a outra parte do ego segue analista, observadorae avaliativa, parte esta capaz de conter a outra que está necessaria momentaneamente doente. 
palavras, encontrar uma via de acesso que decodifique o que elas ainda não conseguem dizer, pois não usam a palavra, ainda não simbolizam; é fazer o que Theodoro soube tão bem fazer nesta história: deixar-se ocupar por Amparo para refazer a unidade mãe-bebê, onde o paciente se torna capaz de ler almas, a sua alma, pois é só através da existência do outro e com o outro que encontramos um pouquinho a técnica para desatar o nó do elástico.

Dessa forma, indago o que há de tão rico nesses pacientes que, apesar de tanto desamparo, ainda estão aqui comigo, oferecendo-me essa oportunidade única de acompanhá-los em tão importante tarefa, de tentar retirá-los desse vazio, desse caos, da não- existência? Certamente, ficarei distante de encontrar a resposta, mas talvez encontremos a ponta da corda que conduza a algum caminho na escolha inconsciente do nome da personagem Amparo, feita pela autora da história que contei aqui. Quando li o livro, fiquei intrigada, pois Amparo, a personagem da história, procura amparo, o que está no nome, mas que ainda não o é na vida, justamente porque lhe faltou amparo! Então, fiz contato com Letícia
Wierzchowski, por e-mail, para indagar-lhe sobre a escolha do nome dessa personagem, ao que ela me respondeu: "A escolha do nome foi uma coisa impensada, um nome latino, uma coisa meio Garcia Marques. Nem sei porque escolhi, mas gosto muito dele. Aliás, gosto muito da personagem Amparo. Me emocionei com a trajetória dela". Talvez essa escolha sirva para nos dizer que sempre existe algum grau de Amparo em meio a tanto desamparo. Quem sabe seja este registro, de mínimo amparo, que faça com que esses pacientes batam às nossas portas, permitindo-nos acompanhá-los.

Se não reconhecermos que nossa tarefa é compartilhar desse mundo pré-verbal auxiliando a transformá-lo em verbal, estaremos sendo injustos com os pacientes que nos procuram. Para concluir, retomo uma frase do livro que aborda essa capacidade de transformação: "Ela bebia-Ihe os risos cálidos e os poemas sussurrados e assim, lentamente, em seu mundo de silêncios, começava a brotar um novo universo ( acrescento - repleto de palavras e significados), porque o sentimento que the nascia fazia crescer sua alma... Nunca mais, para ela, haveria a solidão".
Dessa forma

indagamo-nos o que há de tão rico nesses pacientes que,

apesar de tanto desamparo, ainda estão aqui conosco, oferecendo-nos essa oportunidade única de acompanhá-los em tão importante

tarefa, de tentar retirá-los desse vazio, desse caos, da nãoexistência?

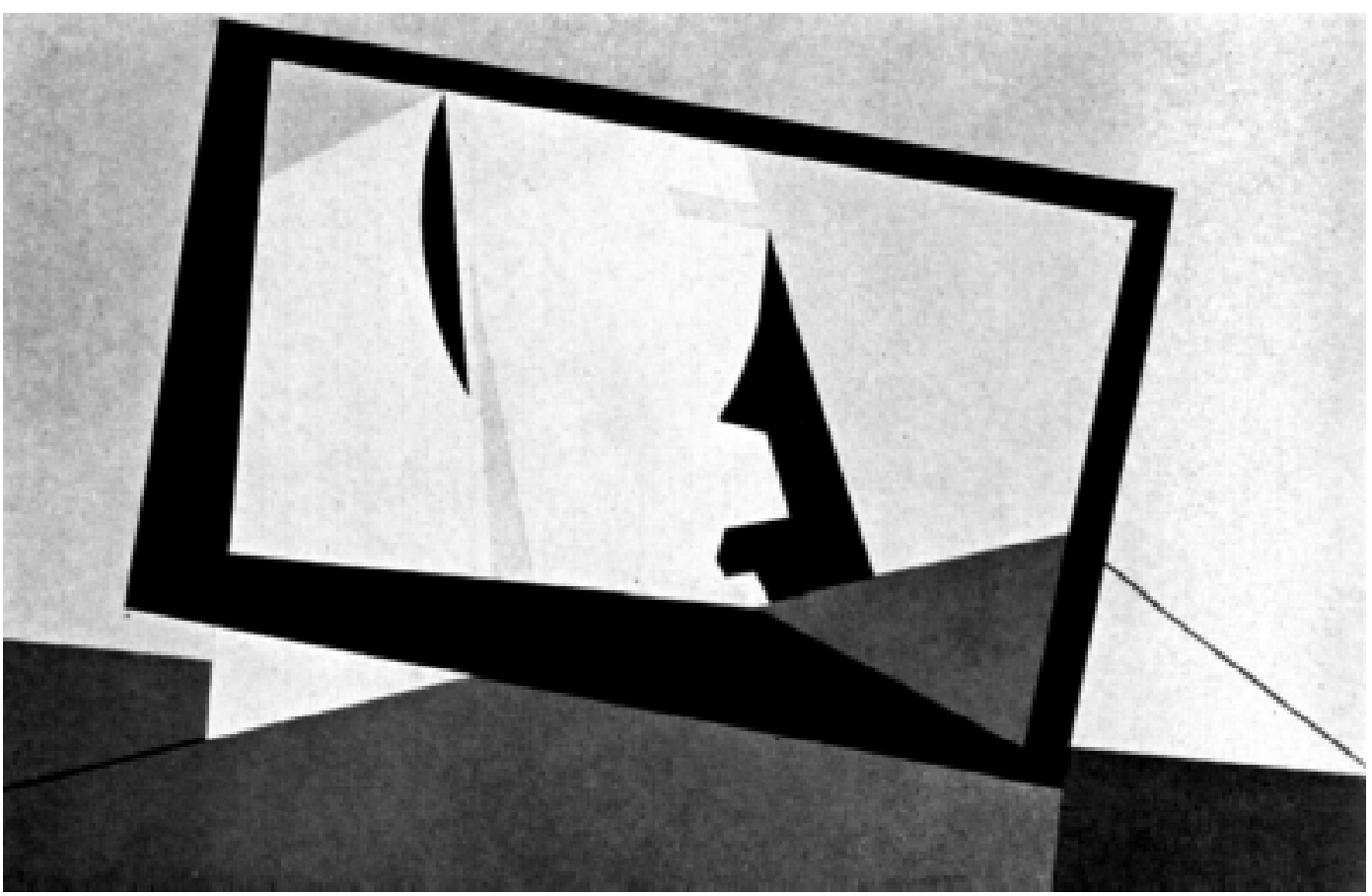


Evanisa Helena Maio de Brum

Rua João Abott 451, sala 204 - Bairro Petrópolis Porto Alegre - Rio Grande do Sul - CEP: 90460-150

Tel.: (51) $91280886-$ (51) 33337820 E-mail:evanisa@brturbo.com

AMERICAN PSYCHIATRIC ASSOCIATION. DSM-IV. Diagnostic and Statistical Manual of Mental Disorder. 4th. ed. revised. Washington, DC, 1995.

BALINT, M.. A Falha Básica.. POA: Artmed,1989 (1968).

BOLLAS, C. A Sombra do Objeto: Psicanálise do Conhecido não Pensado. Rio de Janeiro: Imago, 1987.

FREUD, S. Três Ensaios Sobre a Teoria da Sexualidade. Edição Eletrônica das Obras Psicológicas Completas de Sigmund Freud.. Rio de Janeiro: Imago. CD-Rom, 1999 (1905).

FREUD, S. Fragmento da Análise de um Caso de Histeria. Edição eletrônica das Obras Psicológicas Completas de Sigmund Freud. Rio de Janeiro: Imago. CD-Rom, 1999 (1905b).

FREUD, S. O Ego e o Id. Edição Eletrônica das Obras Psicológicas Completas de Sigmund Freud. Rio de Janeiro: Imago. CD-Rom, 1999 (1923)

FREUD, S. Construções em Análise. Edição Eletrônica das Obras Psicológicas Completas de Sigmund Freud. Rio de Janeiro: Imago. CDRom, 1999 (1937)

GREEN, A. Sobre a Loucura Pessoal. RJ: Imago, 1986.

KHAN, M. The Privacy of the Self. London: Horarth, 1974.

LITTLE, M. Ansiedades Psicóticas e Prevenção: Registro Pessoal de uma Análise com Winnicott. RJ: Imago, 1981.

MALHER, M. O Nascimento Psicológico da Criança. RJ: Zahar, 1975. MASINA, L. Édipo Rei, de Sófodes: Reflexões Acerca de um Texto Fundador.

In SBP DE PA. Freud e suas Leituras. POA: Sociedade Brasileira de Psicanálise de Porto Alegre, 2003, pp. 17-26.
SBPDE PA. Freud e suas Leituras. POA: Sociedade Brasileira de Psicanálise de Porto Alegre, 2003.

WIERZCHOWSKI, L. Prata do Tempo. POA: LPM, 1999.

WINNICOTT, D. Aspectos Clínicos e Metapsicológicos da Regressão no Contexto Psicanalítico. In Winnicott, D. Textos Selecionados da Pediatria à Psicanálise. RJ: Imago, 2000, pp.374-392.

Formas Clínicas da Transferência. In Winnicott, D. Textos Selecionados da Pediatria à Psicanálise. RJ: Imago, 2000 (1955-6), pp.393398.

Preocupação Materna Primária. In Winnicott, D. Textos Selecionados da Pediatria à Psicanálise. RJ: Imago, 2000 (1956), pp.399405 .

. Distorção do Ego em Termos de Falso e Verdadeiro Self. In Winnicott, D. OAmbiente e os Processos de Maturação. POA: Artmed, 1982 (1960), pp.128-139.

.Da Dependência à Independência no Desenvolvimento do Indivíduo. In Winnicott, D. O Ambiente e os Processos de Maturação. POA: Artmed, 1982 (1963a), pp.79-87.

Medo do Colapso. In Winnicott, D. Explorações Psicanalíticas. POA: Artmed, 1994 (1963b), pp.70-76.

$$
\text { . Natureza Humana RJ: Imago,1990 (1971). }
$$

ZIMERMAN, D. Fundamentos Psicanalíticos: Teoria, Técnica e Clínica. POA: Artmed, 1999. $\overline{2001 .}$

. Vocabulário Contemporâneo de Psicanálise. POA: Artmed, 